\title{
LA HISTORIOGRAFÍA CATALANA DEL SIGLO XVIII. LUCES Y SOMBRAS DE UN PROYECTO ILUSTRADO Y NACIONAL
}

\author{
Javier ANTÓN PELAYO \\ Universidad Autónoma de Barcelona
}

\begin{abstract}
Resumen
Este ensayo traza una panorámica de la historiografía catalana durante el siglo XVIII. En primer lugar, se analizan los elementos que la vinculan y la separan del historicismo del Barroco; en segundo lugar, se trazan las vías a partir de las cuales el criticismo bibliográfico y documental llegó al Principado, refrenándose de esta manera el patriotismo del siglo anterior; y, finalmente, se relacionan los principales historiadores de la Ilustración catalana, poniendo de manifiesto el difícil equilibrio entre la crítica histórica y el hecho nacional. Se examinan la labor historiográfica de la Academia de Buenas Letras y la producción de eruditos como Narcís Feliu de la Penya, Josep de Mora, Pere Serra y Postius, Jaume Caresmar, Antoni de Capmany y Joan Francesc Masdeu.
\end{abstract}

\begin{abstract}
Through this essay, Javier Antón Pelayo traces a general view of the Catalan historiography of the Eighteenth Century. Firstly, the author analyses the unifying and the incompatible elements of that historiography in relation to the last Baroque historicism. Secondly, Antón describes the ways in which historical criticism arrived at Catalonia, reducing the former patriotism.Finally, he lists the main Enlightened Catalan historians, always in the dilemma of their historical criticism and their own national feelings. The present article also examines the historiographycal works of an Enlightened Catalan institution (the «Academia de Buenas Letras») and the production of intellectuals as Narcís Feliu de la Penya, Josep de Mora, Pere Serra i Postius, Jaume Caresmar, Antoni de Capmany and Joan Francesc Masdeu.
\end{abstract}

Podría resultar cargante iniciar este ensayo dando un repaso a la historiografía de la historiografía catalana del siglo XVIII pero, entre la parvedad de las reseñas consultadas y el disimulo de las referencias desdeñadas, la relación se presenta escueta y ligera. En primer lugar, porque no puede celebrar una monografía de conjunto 
sobre el tema ${ }^{\prime} y$, por tanto, se tiene que conformar con las menudas y concretas aportaciones que, desperdigadas, han ido apareciendo y, en segundo lugar, porque en algunos casos todavía las referencias clásicas continuan siendo válidas a falta de nuevos estudios que las ratifiquen o las cuestionen. Ciertamente, no ha existido en Cataluña un proyecto de conjunto ni para abordar la historiografía del Setecientos ni la historiografía de ninguna época. No deja de admirar que, entre los dos elementos principales que configuran una realidad nacional, la historia y la lengua, sólo se haya atendido y promocionado la singularidad del segundo. Mientras que existen excelentes historias de la lengua y la literatura catalanas, tanto parciales como de conjunto, la historiografía no dispone todavía de una obra global sobre los historiadores, las corrientes y las instituciones que tanto han colaborado en difundir y cimentar la idiosincrasia catalana. La actualidad mediática de la lengua -con un alegato bastante homogéneo- y la generalizada amnesia histórica -promocionada tal vez por el peligro que entraña la discordancia- han sido dos de las causas que han propiciado que en la cultura catalana contemporánea existan marcados desarrollos diferenciales. A pesar de las carencias, en el día de hoy al menos se puede hablar de una iniciativa esperanzadora, la que dirige el profesor Antoni Simon Tarrés, aún en sus primeras fases, que pretende confeccionar un extenso y completo diccionario de la historiografía catalana. Mientras este proyecto no cobre forma, la bibliografía recolectada y las intenciones planteadas en el título han dado lugar a que este ensayo se organice en tres partes, dentro de las qué se han acogido las propiedades más características de los historiadores catalanes del siglo XVIII y sus principales obras.

La primera parte constituye un imprescindible prolegómeno en donde se plantean las estrechas vinculaciones entre el historicismo del Barroco y la importancia de la historia en la configuración de la nacionalidad catalana. Estas dos circunstancias convergen en Narcís Feliu de la Penya, un historiador muy próximo a la erudición del siglo XVII y todavía muy alejado del criticismo que empezaba a plantearse a nivel internacional. Sobre la historia nacional catalana del Seiscientos existen abundantes aportaciones aunque, recientemente, las investigaciones de Jesús Villanueva y Antoni Simon ${ }^{2}$ han revelado la trascendencia que la construcción histórico-mítica tuvo en la articulación de los planteamientos ideológicos de la Revolución Catalana de 1640. La apelación a la historia como principal recurso definidor de la identidad nacional catalana va a continuar empleándose más o menos abiertamente hasta 1714. En el contex-

1. Sólo los valiosos pero sucintos trabajos de Ramon Grau constituyen una visión de conjunto. Ramon GRAU, «Els intel-lectuals, entre la Il·lustració i les tradicions nacionals» en Borja de RIQUER (dir.), Història. Política, societat i cultura dels Països Catalans, Enciclopèdia Catalana, Barcelona, 1995, vol. 5, pp. 326-343; «Les batalles de la historiografia crítica» en Pere GABRIEL, Història de la Cultura Catalana, Edicions 62, Barcelona, 1996, vol. 3, pp. 163-188.

2. Jesús VILLANUEVA, Los origenes carolíngios de Cataluña en la historiografia y el pensamiento político del siglo XVII, trabajo de doctorado, Universidad Autónoma de Barcelona, Bellaterra, 1994; «Francisco Calça y el mito de la libertad originaria de Cataluña», Revista de Historia Jerónimo Zurita, 69-70 (1994), pp. 75-87; Antoni SIMON I TARRÉS, Els origens ideològics de la revolució catalana de 1640, Publicacions de l'Abadia de Montserrat, Barcelona, 1999. 
to del último tercio del siglo XVII se enmarca la posición del economista ${ }^{3}$, político ${ }^{4}$ $\mathrm{y}$, finalmente, historiador ${ }^{5}$ Feliu de la Penya. Por este orden $-\mathrm{y}$ de manera un tanto nostálgica- ha sido valorada la personalidad de este destacado austracista.

La segunda describe como el dramático desenlace que tuvo para Cataluña la Guerra de Sucesión favoreció la renovación historiográfica. Refrenado el patriotismo catalán, las directrices del criticismo bibliográfico llegaron al Principado a través de la escuela valenciana -magistralmente estudiada por Antonio Mestre ${ }^{6}-$, mientras que las orientaciones del criticismo documental procedieron, sobre todo, de la escuela archivística francesa. Después de señalar los individuos y los canales por los que se movió el nuevo espíritu crítico, se analiza la conjunción de ambos ascendientes -el bibliográfico y el documental- en Josep de Mora, marqués de Llió, alma de la Academia de Buenas Letras de Barcelona hasta su muerte en 1762. Sobre este destacado metodólogo no se ha escrito más que las generalidades que se recogen en los diccionarios, en las obras generales y en las publicaciones de los aniversarios de la Academia $^{7}$. A pesar de padecer el esfuerzo de Josep de Mora ciertos desaires -en especial

3. Pierre VILAR, Catalunya dins l'Espanya Moderna, Edicions 62, Barcelona, 1964-1968 y Le Manual de la Compañya Nova de Gibraltar, París, 1963; Pere MOLAS, «La companyia Feu-Feliu de la Penya (1676-1708). Comerç de teixits i estructura social vers 1700», Cuadernos de Historia Económica de Catalunya, XII (1974), pp. 77-126; Henry KAMEN, «El Fenix de Cataluña: la obra renovadora de Narciso Feliu de la Peña», Estudis, 1 (1972), pp. 185-203 y el estudio introductorio titulado «Narcís Feliu de la Penya i el "Fénix de Cataluña"» de la obra de Narcís FELIU DE LA PENYA, Fénix de Cataluña, Departament de Cultura de la Generalitat de Catalunya, Barcelona, 1983, pp. 5-31.

4. Maria GRAU I SALÓ, «Feliu de la Penya: una visió actual de Catalunya com a país», Pedralhes, 7 (1987), pp. 125-145; Joaquim ALBAREDA, Els catalans $i$ Felip $V$, de la conspiració a la revolta (1700-1705), Barcelona, 1993.

5. Fernando SÁNCHEZ MARCOS, «Historia y política en el umbral del siglo XVIII: los Anales y combates por Cataluña de N. Feliu de la Penya», Mémoires de la Société Archéologique de Montpellier (Actes du XII Congrès d'Histoire de la Couronne d'Aragon. Montpellier 26-29 septembre 1985, vol. 3, Historiographie), Montpellier, vol. 17 (1989), pp. 133-146; Eva SERRA, «Una aproximació a la historiografia catalana. Els antecedents», Revista de Catalunya, 26 (enero 1989), pp. $29-46$ (especialmente las páginas 31-33); Jordi CORTADELLA, La historiografia antiga en la historiografia catalana, tesis doctoral, Universidad Autónoma de Barcelona, Bellaterra, 1991, vol. 1, pp. 154-161; y Eulàlia DURAN, «Narcís Feliu de la Penya, historiador i polític», Afers, 20 (1995), pp. 73-86.

6. Sobre la historiografía española del siglo XVIII y el foco valenciano son de imprescindible consulta los trabajos de Antonio Mestre: su tesis doctoral, Historia, fueros y actitudes políticas. Mayans y la historiografía del XVIII, Publicaciones del Ayuntamiento de Oliva, Valencia, 1970; su trabajo sobre Martí y el círculo alicantino, Humanismo y crítica histórica en los ilustrados alicantinos, Universidad de Alicante, Alicante, 1980; y las síntesis, «Mayans, historiador» en Gregorio Mayans y Siscar, Obras completas. I. Historia, Publicaciones del Ayuntamiento de Oliva, Valencia, 1983, pp. 21-31 y «Conciencia histórica e historiografía» en Historia de España de Menendez Pidal, Espasa-Calpe, Madrid, 1988, tomo 31, vol. 1, pp. 299-345; «Crítica y apología en la historiografía de los novatores», Studia Histórica. Historia Moderna, 14 (ler semestre 1996), pp. 45-62.

7. Josep R. CARRERAS Y BULBENA, «Josep de Mora y de Catà, marquès de Llió», Boletín de la Real Academia de Buenas Letras de Barcelona, 13 (1927-1928), pp. 192-197; VV.AA., Historia y labor de la Real Academia de Buenas Letras de Barcelona desde su fundación en el siglo XVIII, Real Academia de Buenas Letras, Barcelona, 1953, especialmente las pp. 55-58 de Ramon d'Abadal; Antoni COMAS, Historia de la literatura catalana. Part moderna, Ariel, Barcelona, 1985, vol. 5, pp. 160-161. 
del círculo erudito de la Universidad de Cervera- su labor supuso un próximo aldabón para la historiografía crítica catalana, tanto eclesiástica como civil, de los reinados de Carlos III y Carlos IV.

La tercera se refiere al rendimiento de los ilustrados - «lustrados de cultura»-catalanes durante el siglo XVIII, poniendo de manifiesto las desiguales vinculaciones al movimiento criticista y al hecho nacional. El desarrollo de ambos a lo largo de la centuria va a ocasionar combinaciones muy particulares y conclusiones muy diversas. Pere Serra i Postius (1671-1748) representaría la posición más difusa dentro de esa tendencia. Valorado en el pasado como formidable erudito o recolector de noticias, suele ser en la actualidad empleado como ejemplo paradigmático del providencialismo y la escasa fundamentación histórica que todavía persiste en Cataluña durante la primera mitad del XVIII ${ }^{8}$. La vocación historiográfica de Jaume Caresmar (17171791) se circunscribe al ámbito de la erudición, es decir, a la exhumación de documentos y al análisis crítico de los mismos. El principal estudio sobre la obra y la personalidad del erudito de Bellpuig de las Avellanas es el realizado por Eduard Corredera, ministro del mismo monasterio premostratense ${ }^{9}$. El resto de las contribuciones sobre Caresmar -y sus discípulos Jaume Pasqual y Josep Martí- son análisis más parciales que adoptan el tono reivindicativo de aquellos que desempolvan noticias olvidadas, tal y como lo hiciera en su momento el propio personaje estudiado ${ }^{10}$. Finalmente, asumiendo, aunque superando, la pasión por el documento, se hallan los historiadores propiamente dichos según el sentido moderno de la palabra, es decir, los que elaboran sus trabajos con un elegante y original discurso -abstrayéndose de la literalidad de los documentos-, con un fuerte componente reflexivo basado en la verosimilitud y con una ampliación del objeto de estudio. Entre estos historiadores sobresalen

8. Josep Finestres, Gregorio Mayans, Félix Torres Amat, Raimon Ferrer, Andreu Avelí Pi i Arimon -durante el siglo XVIII y principios del XIX- valoraron positivamente las obras de Serra i Postius por constituir éstas un interesante y cómodo almacén de datos. Los reparos a su labor, delatando la escasa crítica de sus trabajos, comienzan en 1929 con Ramón. D. Perés y han continuado hasta la actualidad en los análisis de Stiffoni y Mestre. Ramon D. PERÉS, «Pere Serra y Postius. El perqué de Barcelona y memories de ses antigüetats», Boletín de la Real Academia de Buenas Letras de Barcelona, 9 (1929), pp. 7-16; Giovanni STIFFONI, Verità della storia e ragioni del potere nella Spagna del primo 700, Franco Angeli, Milán, 1989 y Antonio MESTRE, «La Iglesia en la España de los siglo XVIJ y XVIII» en Historia de la Iglesia en España, Biblioteca de Autores Cristianos, Madrid, 1975, vol. 4, pp. 603-604. La aportación más reciente sobre Serra i Postius reivindica su relación con la corriente criticista. José Luis BETRÁN, Antonio ESPINO y Lluís Ferran TOLEDANO, «Pere Serra i Postius y el criticismo historiográfico en la Barcelona de la primera mitad del siglo XVIL», Manuscrits. Revista d'Història Moderna, 10 (1992), pp. 315-329.

9. Eduard CORREDERA GUTIÉRREZ, La Escuela Histórica Avellanense, Balmes, Barcelona, 1962. El mismo autor ha publicado más aportaciones sobre el mismo tema, sobre todo, en la revista Analecta Sacra Tarraconensia de los años 1964, 1965, 1966 y 1974.

10. Joan MERCADER I RIBA, Un igualadí del segle XVIII: Jaume Caresmar, Estudis Comarcals, Igualada, 1947 y Historiadors $i$ erudits a Catalunya i a Valènca en el segle XVIII, Rafel Dalmau, Barcelona, 1966. El estudio más reciente, especialmente útil por la relación de los manuscritos y documentos de archivo de Caresmar es el de Marina GARÍ, Raimon MASDEU y Manuela URBINA, «Jaume Caresmar. L'home i la seva obra», Manuscrits. Revista d'Història Moderna, 10 (1992), pp. 331-371. 
Antoni de Capmany (1742-1813) y Joan Francesc Masdeu (1744-1817). Dos ilustres figuras que, sin embargo, han tenido un tratamiento muy desigual por parte de la historiografía. Mientras Masdeu ha recibido una atención discreta ", Capmany ha sido objeto en los últimos años de numerosos estudios que han cubierto la mayoría de sus facetas. De todas ellas, la de historiador ha resultado ser la menos polémica, tal vez por haberse restablecido su mérito recientemente. Condenado al ostracismo por los estudiosos del siglo XIX, que no comprendieron la aparente contradicción de sus posicionamientos, y dejando de lado las loas vertidas en los homenajes conmemorativos correspondientes, el primer trabajo que reivindicó la originalidad y la modernidad de la técnica histórica de Capmany fue el de Pierre Vilar en $1933^{12}$. Después de esta primera revelación y al margen de las noticas que traen las valoraciones historiográficas generales ${ }^{13}$, en el contexto de los años sesenta se vuelve sobre la obra de Capmany ${ }^{14}$ pero no es hasta finales de los años setenta y principios de los ochenta que no se comenzarán a hacer las primeras aproximaciones a su pensamiento historiográfico. Aquí se inscriben los bosquejos de Ramon Grau y Marina López ${ }^{i 5}$ y, después, los pri-

11. Una aproximación al personaje en Ramon GRAU y Marina LÓPEZ, «Joan Francesc de Masdeu i de Montero» en Francesc ARTAL, Pere GABRIEL, Enric LLUCH y Francese ROCA (dirs.), Ictineu. Diccionari de les Ciències de la Societat als Països Catalans, Edicions 62, Barcelona, 1979, pp. 300302 y en Ramon GRAU, «Joan Francesc de Masdeu i de Montero» en Jesús MESTRE I CAMPÍ (dir.), Diccionari d'Història de Catalunya, Edicions 62, Barcelona, 1993. Estudios más minuciosos desde una óptica historiográfica y nacional son los artículos de Roberto MANTELLI, «L'us de la crítica en els escrits de l'historiador català Joan Francesc de Masdéu», Recerques, 11 (1981), pp. 137-148 y «Nationalism, xenophobia and catalanism in the writings of an Enlightened catholic historian: Juan Francisco Masdeu, S.J. (1744-1817)», Analecta Sacra Tarraconensia, 55-56 (1982-1983), pp. 209260.

12. Pierre VILAR, «L'obra de Capmany, model de mètode històric. La historia catalana del segle XVIII», Butlleti del Centre Excursionista de Catalunya, 43 (1933), pp. 146-154. Reeditado en Assaigs sobre la Catalunya del segle XVIII, Curial, Barcelona, 1983, pp. 83-90 con el título «Capmany i el naixement del mètode històric».

13. José Antonio MARAVALL, «Mentalidad burguesa e idea de la Historia en el siglo XVIII», Revista de Occidente, 107 (febrero 1972), pp. 250-286.

14. Entre 1961 y 1963, la Cámara Oficial de Comercio y Navegación de Barcelona reeditó las Memorias históricas de Capmany, edición que corrió a cargo de Emili Girait y Carme Batlle. Emili Giralt publicó en 1965 una selección de textos de Capmany, Ideari d'Antoni Capmany (Ed. 62, Barcelona). Fernando Sánchez Marcos considera que el contexto de los años sesenta invitaba a la recuperación de las obras del historiador setecentista ya que «era una época de desarrollo económico, de un cierto reavivamiento de la conciencia de catalanidad, y de los inicios de la influencia de la escuela de los Annales... en la historiografía universitaria española», Fernando SÁNCHEZ MARCOS, «La historiografía del siglo XVIII como espejo del antiguo régimen: consideraciones sobre las "Memorias históricas" de A. de Capmany y el compendio de "Historia universal" de C. Buffier" en Actas del Coloquio Internacional Carlos III y su siglo (Madrid, 14-17 noviembre 1988), Departamento de Historia Moderna de la Universidad Complutense, Madrid, 1990, vol. 1, p. 97.

15. Ramon GRAU y Marina LÓPEZ, «Antoni de Capmany de Montpalau i Suris» en Francesc ARTAL, Pere GABRIEL, Enric LLUCH y Francesc ROCA (dirs.), Ictineu..., 1979, pp. 98-100 y «EI pensament historiogràfic d'Antoni de Capmany: de la Il-Justració al Romanticisme», I Congrés d'Història Modema de Catalunya, Universitat de Barcelona, Barcelona, 1984, vol. 2, pp. 589-596. 
meros estudios de una cierta profundidad sobre los vínculos metodológicos de Capmany ${ }^{16}$. Todo ello a Josep Fontana le parecía poco en 1988, sobre todo considerando el interés de este historiador y sus obras en relación a otros autores que habían recibido mayor atención -como Feliu de la Penya y su Fénix de Cataluña-, aún siendo de valía muy inferior ${ }^{17}$. A principios de los noventa, dos trabajos -de corte ideológico muy diferente- han terminado haciendo justicia a la importancia del personaje ${ }^{18}$.

Éstos son los principales «lustrados de cultura» sensibles a la temática histórica. Todos ellos formaron parte de la Academia de Buenas Letras de Barcelona, una institución de corte muy heterogéneo en donde se refugiaron multitud de eruditos al amparo de proyectos que nunca acabaron de cuajar ${ }^{12}$. Después de considerar la importancia de esta institución, se valora el compromiso nacional de alguno de los miembros menos conocidos, en relación a los cuatro historiadores anteriores y, en especial, a las formulaciones histórico-políticas del canónigo Francesc Dorca y otros individuos del grupo cerverino.

\section{LOS ORÍGENES DE LA APASIONADA HISTORIA NACIONAL DEL BARROCO Y NARCÍS FELIU DE LA PENYA}

Desde los umbrales de la modernidad, el relato histórico ofreció un trascendental servicio a las configuraciones nacionales. Aun así, la fortaleza política de unas naciones tuvo la capacidad de supeditar los elementos diferenciales de otras a un origen y un destino común, promocionando articulaciones estatalistas y forjando objetivos imperialistas. La Corona de Castilla desde la Edad Media había auspiciado una historia nacional tan mítica y legendaria como las del resto de las naciones pero, tras la unión dinástica de los Reyes Católicos y con la particular castellanización de Felipe II ${ }^{20}$, trató de aglutinar los fastos del resto de los reinos españoles, consiguió apropiarse del

16. Isabel ROMÁ RIBES, «Influencia de L.A. Muratori en la metodología crítica de Antoni Capmany», Revista de Historia Moderna. Anales de la Universidad de Alicante, 3 (1983), pp. 383-407 y «Muratori y Capmany: de la crítica erudita al análisis histórico», Pedralbes, 4 (1984), pp. 161-186; Fernando SÁNCHEZ MARCOS, «La historiografía del siglo XVIIl...», 1990, pp. 91-101.

17. Josep FONTANA, «Estudi preliminar» en Antoni de CAPMANY, Cuestiones críticas sobre varios puntos de historia económica, política y militar, Alta Fulla, Barcelona, 1988, pp. 5-15.

18. Ramon GRAU, Antoni de Capmany i la renovació de l'historicisme polític català, Ajuntament de Barcelona, Barcelona, 1994. También es analizado en su heterogeneidad en la obra de Francisco José FERNÁNDEZ DE LA CIGOÑA y Estanislao CANTERO NÚÑEZ, Antonio de Capmany (1742. 1813). Pensamiento, obra histórica, política y jurídica, Fundación Elias de Tejada y Erasmo de Percopo, Madrid, 1993. En este estudio se valoran explícitamente las opiniones de 56 historiadores sobre Capmany y su obra.

19. Sobre la Academia de Buenas Letras de Barcelona, Martí de RIQUER, Historia y labor de la Real Academia de Buenas Letras de Barcelona...,1953, pp. 275-304; Miguel PÉREZ LATRE y David ASENSIO VILARÓ, «Cultura histórica en Cataluña: el caso de la Real Academia de Buenas Letras de Barcelona, entre 1752 y 1799» en Pedralbes. Actes Segón Congrés d'Història Moderna de Catalunya. Catalunya a l'època de Carles III, 8-2 (1988), pp. 227-243.

20. José Luis GONZALO SÁNCHEZ-MOLERO, «Princeps Hispaniarum: la castellanización de un príncipe Habsburgo (1527-1547)», Manuscrits. Revista d'Història Moderna, 16 (1998), pp. 65-85. 
concepto geográfico de España y logró acaparar para sí a la institución monárquica. Las obras de Florián de Ocampo, Hernando del Pulgar, Diego de Valera, Gonzalo Fernández de Oviedo, Juan Sedeño, Luca Marineo, Esteban de Garibay y tantos otros historiadores castellano-españolistas, impulsaron una historia de España en qué los grandes acontecimientos de la Península Ibérica se relacionaban exclusivamente con Castilla y los de Castilla se hacían extensivos a su vez al conjunto de la Península. Entre los mitos, no suele faltar el del célebre Don Pelayo, convertido en ancestro de los monarcas modernos y portador, para los historiadores de finales del siglo XVII y del siglo XVIII, de una concepción política absolutista emanada de su particular victoria frente a los moros ya que, al conseguir su poder mediante derecho de ocupación y su reino mediante el favor milagroso de Dios, la potestad pudo ser transferida a sus sucesores de manera directa (teoría descendente o teocrática de gobierno), alterándose de este modo el poder electivo de los godos.

Esta capitalización de Dios, Rey y España por parte de Castilla tuvo una contundente réplica por parte de los humanistas catalanes del Renacimiento. Historiadores como Joan Margarit, Martí d'Ivarra, Pere Miquel Carbonell o Cristòfol Despuig se esforzaron en destacar las singularidades de Cataluña -la mejor provincia de España-, de entre las que se hallaba el particular proceso de reconquista. La expulsión de los musulmanes, según la versión de los cronistas catalanes, se llevó a cabo por el conde Guifré el Pilós y sus súbditos de manera autónoma, sin que existiera ningún tipo de vinculación a un poder superior (teoría ascendente o popular de gobierno). Estas divergencias historiográficas entre los historiadores catalanes y castellano-españolistas a lo largo de la segunda mitad del siglo XVI y la primera del XVII, cuando se desarrollaron los enfrentamientos político-institucionales entre el Principado y la Monarquía, van a ir alcanzando tonos cada vez más radicales y articulando una contraidentidad entre los dos reinos. En este proceso, en la década de los ochenta del siglo XVI, se propuso un nuevo relato sobre los orígenes medievales de Cataluña fundamentado en el precepto que Carlos el Calvo dió a los «hispani» de la Marca Hispánica en el año 844. Este documento, del cual se conservaba una copia en el Liber antiquitatum del Archivo de la Catedral de Barcelona, explicaba como tras el derrumbamiento de la monarquía visigoda, los habitantes de la futura Cataluña, por su propia cuenta y sin el auxilio de ningún príncipe, emprendieron la reconquista del país invadido por los musulmanes. Después de concluida ésta, solicitaron protección a los reyes de Francia a los que se sometieron mediante una entrega espontánea y voluntaria, aunque condicionada por una serie de pactos, entre los que se hallaban la preservación de la legislación propia y ciertos privilegios fiscales. Francesc de Calça fue el divulgador de esta nueva versión sobre los orígenes histórico-míticos de Cataluña que los historiadores del siglo XVII se encargaron de recoger. No sólo los autores previos al estallido revolucionario de 1640 -como Pere Gil, Francesc Diago y Jeroni Pujades-, o los que escribieron con fines más publicitarios durante el conflicto -como Gaspar Sala y Francesc Martí i Viladamor-, sino también los historiadores del reinado de Carlos II - como Manel Marcillo, Gaspar Roig i Jalpí o Narcís Feliu de la Penya- continuaron blandiendo estos planteamientos. Durante el período neoforalista 
persistió el propósito firme de hacer renacer de entre las cenizas del olvido la memoria de las hazañas de los catalanes, enfriadas por la derrota de 1652, aunque para tal fin se asumiese el simple crédito -escribía Marcillo en su Crisi de Cataluña-que merecen las historias humanas y así falibles ${ }^{21}$.

Si bien los historiadores del siglo XVII continuaron exhibiendo con orgullo en sus prólogos aquella consecuente máxima que proclamaba que «la verdad es el alma de la historia», en la práctica, el espíritu que dominó la historiografía del Barroco fue el de la parcialidad, el encono y la tendenciosidad. Una historia tan comprometida en la defensa de las gloriosas singularidades de la patria (ya sea estado, nación, país, ciudad o corporación) que muchos historiadores no tuvieron reparos en confiar en fuentes inciertas o sospechosas, forzando, en numerosas ocasiones, interpretaciones especulativas o imaginarias y narrando con la vehemencia y la subjetividad del que participa más del género panfletario que del género histórico. El amor patrio, aliñado con la preponderancia y la excelencia en el proceso de criatianización, creó un subgénero de narraciones muy populares -los cronicones- destinado a halagar la devoción y la vanidad de los pueblos. Cuando las fuentes velaban ciertos temas que precisaban urgentes soluciones, los falsarios las fantaseaban dejándolas de este modo al arbitrio de los publicistas políticos de la convulsa centuria del Seiscientos. Por su parte, la erudición de los historiadores fue engullendo los infundios, esforzándose no tanto en refutar como en conciliar las discordancias y en pulir la exactitud de las citaciones ${ }^{22}$. No es extraño, por consiguiente, que la acumulación actuase como factor regresivo y que, por ejemplo, desde la Corónica Universal del Principat de Catalunya de Jeroni Pujades, publicada en 1609, hasta los Anales de Cataluña de Narcís Feliu de la Penya, publicados un siglo después, el acopio de confusiones y ambigüedades hayan actuado en perjuicio de la segunda obra, pues no se aprecia en ésta progreso alguno sobre la primera ${ }^{23}$.

Entre la nómina de historiadores del siglo XVIII, Feliu de la Penya personifica la expiración del periodo cronístico de la historiografía catalana, pero no la desaparición del historicismo, ya que éste continuó con un cierto vigor durante la centuria. Este hecho se demuestra por el prestigio y la difusión de las obras de Feliu entre los intelectuales del Setecientos y por la influencia que alcanzaría entre los sectores historiográficos más populares. En el primer caso, bosquejando las bibliotecas particulares catalanas del Setecientos, se puede comprobar que, aunque las historias de España -sobre todo las de Mariana y Duchesne- fueron muy habituales, también destaca la presencia de los Anales de Cataluña de Feliu, a pesar de la prohibición que pesó so-

21. Manuel MARCILLO, Crisi de Cataluña hecha por las naciones estrangeras, Mathevat, Barcelona, 1685 (protesta del autor).

22. Sobre la historiografía del Barroco en España puede consultarse a José CEPEDA ADÁN, «La historiografía», Historia de España de Menéndez Pidal, Madrid, Espasa-Calpe, 1988, tom. 26, vol. 1, pp. 525-643.

23. Ramon GRAU, «Les batalles...», 1996, p. 168. 
bre ella después de la Guerra de Sucesión por las simpatías austracistas del autor ${ }^{24}$. En el segundo caso, porque el historicismo político pervivió de forma larvada entre los juristas catalanes como Francesc Ametller, Josep Francesc d'Alòs o Ramon Llàtzer de Dou y, finalmente, porque una parte de la historiografía catalana -Pere Serra i Postius, por ejemplo- continuó dentro de una linea todavía con tonos muy barrocos ${ }^{25}$.

Para la mentalidad científica, la obra histórica de Feliu tiene muchos puntos oscuros: los datos proceden básicamente de una erudición libresca que prima el acopio al criterio, en qué no existen reparos a la hora de aceptar episodios dudosos, extravagantes, quiméricos o, por supuesto, milagrosos. Sus fuentes proceden de las principales historias de Cataluña: sigue y cita a Jeroni Pujades, Manel Marcillo, Esteve de Corbera, Pere de Marca, Joan Gaspar Roig i Jalpí, Jerónimo Zurita y las crónicas medievales y no cita, aunque sigue -como ha demostrado Eulàlia Duran-, la Noticia Universal de Cataluña del publicista Francesc Martí i Viladamor, uno de los principales textos justificativos de la revolución política catalana de 1640 . Si no lo menciona es porque el atractivo argumento de Martí se ve empañado al final por una implicación gala ${ }^{26}$ que, a finales del XVII, después de las intrusiones bélicas de Luis XIV en el Principado, no se podía admitir. Por supuesto también cita a los que impugna y entre ellos destacan dos libros escritos durante el conflicto por dos autores filipistas. Uno es la Idea del Principado de Cataluña del aragonés José Pellicer de Ossau y Tovar y el otro, la Cataluña desengañada del canónigo tortosino Alexandre Ros. Para Feliu era inadmisible la idea que defendían estos dos autores de que un rey francés, Luis el Piadoso, hubiese liberado a Cataluña de los sarracenos, desvirtuando de este modo los orígenes del pactismo y el mito de la libertad originaria de los catalanes. Las refutaciones de Feliu, sin embargo, no sólo se refieren a cuestiones históricas. En la parte final del volumen tercero, cuando empieza a narrar a partir del sitio francés de Barcelona de 1697, el relato adopta un tono rememorativo y político. Trata de impugnar el ofensivo libro contra Cataluña del canónigo parisino Luis Legendre titulado Essai du règne de Louis le Grand y, paralelamente, tras la muerte del encumbrado Carlos II, expone sus recelos hacia el candidato francés duque de Anjou y sus preferencias por el archiduque Carlos.

Por todo ello, Eulàlia Duran considera que los Anales de Cataluña de Feliu, más que una obra histórica, es un discurso político con argumentaciones históricas. Se integra plenamente en la literatura de combate, patriótica, típica del Barroco, en donde la crítica histórica es desterrada por inoportuna y la ficción es amparada como ingrediente retórico al servicio de la política y de un ambicioso proyecto económico ${ }^{27}$.

24. Javier ANTÓN PELAYO, La herencia cultural. Alfabetización y lectura en la ciudad de Girona (1747-1807), Monografies Manuscrits-Universitat Autònoma de Barcelona, Bellaterra, 1998 y Javier BURGOS RINCÓN, Imprenta y cultura del libro en la Barcelona del Setecientos (1680-1808), tesis doctoral, Universidad Autónoma de Barcelona, Bellaterra, 1993, vol. 1, p. 724.

25. Ramon GRAU, «Els intel-lectuals...», 1995, pp. 328-334.

26. Javier ANTÓN PELAYO y Montse JIMÉNEZ SUREDA, «Francisco Martí y Viladamor: un profrancés durante ia "Guerra dels Segadors"”, Manuscrits. Revista d'Història Moderna, 9 (1991), pp. 289-304.

27. Eulàlia DURAN, «Narcís Feliu...», 1995, p. 77-79. 
DE LLIÓ

Como ha señalado Ramon Grau, la genealogía del criticismo en Cataluña integra dos ramas principales, la bibliográfica y la documental. La primera, que se basa en el análisis crítico de los historiadores anteriores, llegó a Cataluña desde España a través de la escuela valenciana y la segunda, fundamentada en el estudio de las fuentes primarias, fue más bien un tributo de la escuela archivística francesa ${ }^{28}$. De todos modos, el origen del impulso crítico hay que buscarlo en la historia eclesiástica y, de manera particular, en las revisiones hagiográficas que algunas comunidades religiosas, como los bolandistas o los maurinos, llevaron a cabo a partir de la década de los cuarenta del siglo XVII. El espíritu que animó a estos historiadores fue la revisión sistemática de las aserciones que los historiadores habían mantenido hasta entonces, validando tan solo aquellas que se pudiesen demostrar mediante documentos acreditados. La depuración se llevó a cabo aplicando con rigor las técnicas de verificación de documentos, es decir, las llamadas ciencias auxiliares de la historia, tales como la epigrafía, la paleografía, la sigilografía, la cronología o la diplomática. Junto a este perfeccionamiento del método, también existió un esfuerzo considerable por publicar documentos originales, por recoger exhaustivamente todas las fuentes relativas a cada tema, un especial cuidado en la exactitud filológica de las citaciones y un abandono de la belleza narrativa por contraste a la importancia que ésta había alcanzado entre los historiadores humanistas ${ }^{29}$.

El promotor de la crítica histórica en España fue Nicolás Antonio. Este canónigo sevillano, beneficiario de las ideas bolandistas, actuó como paladín de las reprobaciones contra los sucesos más inverosímiles de ciertos cronicones. En esta misma labor emplearon comprometidos esfuerzos sus condiscípulos Gaspar Ibáñez de Segovia, marqués de Mondéjar, y el benedictino José Sáenz de Aguirre. Convencidos de que las invenciones históricas iban en detrimento de las glorias nacionales, sus escritos se emplearon a fondo para desenmascarar las historias fabulosas y los falsos cronicones. Esta iniciativa, sin embargo, fue una empresa minoritaria y apasionadamente contestada en el contexto histórico del Barroco hispano, pues la mayor parte de los publicistas consideraba legítimo adulterar la historia si esta iba en beneficio de la religión y de la patria. Las controversias se recrudecían cuando se cuestionaban eventos fundamentales por su popularidad, como la venida del apóstol Santiago a la Península o la fundación del orden carmelita por el profeta Elías.

En los críticos de finales del Barroco -los novatores-se aprecia, en definitiva, un proyecto de renovación cultural, estimulado, además, por el estigma de la reconocida decadencia española y por la emulación frente a Europa. Dentro de estas intenciones, el acrisolamiento de la historia pretendía ser una forma de demostrar, sólo mediante certezas, la eminencia de la nación española. En este sentido, la mayoría de

28. Ramon GRAU, «les batalles...», 1996, pp. 169-172.

29. José CEPEDA ADÁN, «La historiografía»..., 1988, pp. 529-531. 
los novatores no pudo sustraerse a ejercer una actividad patriótica basada en la primacía castellana sobre el conjunto de la monarquía. Mondéjar, por ejemplo, cuando se refiere a la reconquista, aunque cuestiona ciertos aspectos, no duda de la existencia y de la importancia de Don Pelayo. Este acendramiento y posterior validación de los orígenes castellano-españoles se contrapone -según Mondéjar- a las sombras que planean sobre los orígenes de los otros reinos. Desde una óptica histórico-política, por tanto, no se puede adular al criticismo español de una absoluta asepsia y, en el fondo, es en este punto donde se hallaba el nido de una buena parte de las adulteraciones históricas ${ }^{30}$.

El criticismo bibliográfico español, que durante el reinado de Carlos II había tenido su foco principal en Andalucía, con el cambio de siglo va a trasladarse a Valencia de la mano de Manuel Martí, un colaborador del cardenal Sáenz de Aguirre. Martí, desde su deanato de Alicante, consiguió crear un círculo de intelectuales de entre cuales destacan el dominico Jacinto Segura y, su principal discípulo, Gregorio Mayans. En el año 1733, Segura publicó el Norte crítico, la más destacada obra de metodología histórica del Setecientos, un maduro testimonio del sentido crítico que destaca por la exhaustiva valoración que realiza de las pruebas del pasado, a pesar de que en casos concretos se adviertan deficiencias, como por ejemplo, en la defensa de las tradiciones jacobeas, consecuencia del peso que continuaban teniendo los atavismos piadosos y religiosos ${ }^{31}$.

Más contundente será la actitud de Mayans frente a los infundios contenidos en los falsos cronicones. Sus dos iniciativas principales en el campo de la historia, la divulgación del método crítico y la publicación de las fuentes originales, serán obstinadamente acosadas por la intelectualidad defensora de las creencias populares y terminaran desamparadas por el gobierno borbónico. La corte no estuvo dispuesta a favorecer un método crítico que cuestionase las glorias nacionales y las tradiciones populares. No deben extrañar, por tanto, sus frecuentes polémicas con intelectuales orgánicos como Feijoo o el padre Flórez. Como señala Mestre, el nacionalismo de Mayans se alimentaba de glorias verídicas mientras que el nacionalismo de sus oponentes se basaba muchas veces en glorias fantásticas. La actitud crítica de Mayans le reportó incluso la acusación de antiespañol y, ante el poder de sus contrarios, se vió obligado a retirarse a la villa de Oliva, donde continuó su empeño crítico a través del más reservado género epistolar. Las misivas de Mayans ejercieron un saludable influjo en el ambiente cultural catalán, particularmente en los obispos de Barcelona Asensi Sales y Josep Climent, en el fiscal de la Audiencia Manel Sisternes y en Josep Finestres y el círculo cerverino.

30. Antonio MESTRE, «Crónica y apología...», 1996, pp. 54-57.

31. El título completo de la obra de Jacinto Segura es Norte crítico con las reglas más ciertas para la discreción en la Historia y un Tratado Preliminar para la instrucción de históricos principiantes, José García, Valencia, 1733. Sobre Segura existe el estudio aproximativo de Jaume Pastor i Fluxà, Fr. Jacinto Segura (1668-1751): el «Norte Crítico» y las polémicas con Sales, Caja de Ahorros Provincial de Alicante, Alicante, 1986. 
A este aporte valenciano, sobre todo en lo que respecta a crítica bibliográfica, hay que añadir la vinculación catalana a la escuela archivística francesa, contribución que acabó siendo la más vigorosa del criticismo historiográfico del Principado. Coloboró en esta primacía la riqueza documental de los archivos catalanes, una particularidad que ya detectaron Pere de Marca y su colaborador Étienne Baluze. Estos dos personajes formaron parte de la pléyade de historiadores franceses que, bajo el impulso de Richelieu, Mazarino y Luis XIV, fueron instados a revisar los títulos y derechos de los reyes franceses en los territorios fronterizos. Marca, por ejemplo, trabajó en los archivos catalanes durante los años 1644 a 1651 y en sus trabajos se esforzó por reivindicar los orígenes franceses de Cataluña y la acción de Francia en el Principado.

Al margen de la posición política de ambos autores, la nueva técnica archivística que abanderaban influyó decisivamente entre los archiveros catalanes. La proclama que pregonaban se basaba en una cuidadosa labor de recopilación de los documentos, la publicación de los diplomas y la depuración de los textos. En esta linea de actuación se inscribe la actividad de Josep de Taverner i d'Àrdena, Manel Marià Ribera, Francesc Xavier Garma ${ }^{32}$ y Jaume Caresmar, el canónigo premostatense fundador de la escuela de archiveros de Bellpuig de las Avellanas. El esfuerzo de estos eruditos de principios del siglo XVIII va a contribuir de manera decisiva en la fortaleza y preponderancia del criticismo documental frente al criticismo bibliográfico.

De todos modos, no faltaron provechosas combinaciones entre las dos tendencias y maduras elaboraciones teóricas. En este punto intermedio destaca Josep de Mora i Catà (1694-1762), marqués de Llió, presidente de la Academia de Buenas Letras y autor de un tratado titulado Observaciones sobre los principios elementales de la historia, incluido dentro del primer volumen de las Memorias de la Academia del año 1756. La primera parte del trabajo sigue la línea de la crítica bibliográfica desarrollada por la escuela valenciana y la segunda es un tratado de paleografía y diplomática. Inicia sus Observaciones declarándose seguidor de Nicolás Antonio, Juan de Ferreras, el marqués de Mondéjar y el padre Jacinto Segura; continúa después exponiendo las cualidades y las circunstancias que han de concurrir en un buen historiador, atendiendo inicialmente a la relación de éste con su patria. Sobre este particular plantea las siguientes prevenciones:

«El primer encuentro del examen crítico de un autor, es su patria. Ésta exige tres cuydados, porque tiene tres inspecciones: la primera, concerniente al nativo impulso de

32. Taverner (1670-1726) fue canónigo de la catedral de Barcelona y obispo de Gerona. Actúo en favor de la causa borbónica. Como consecuencia de sus investigaciones archivísticas escribió Compendi dels antics monastirs $i$ esglèsies dels comtats de Rosselló, Empúries i Peralada y Arbre genealògic dels comtes de Roselló, Peralada y Empúries, de entre otras obras sobre la misma temática. Ribera (1652-1736), fraile mercedario, especulador del Archivo Real de Barcelona y miembro de la Academia de Buenas Letras. Escribió muchas obras, de entre las cuales destacan Real Capilla de Barcelona, Real instituto del orden de la Merced y Vida de Santa Maria de Cervelló. Garma (1708-1783), heraldista y archivero de la Corona de Aragón. Escribió Adarga catalana y Tratado de los sellos. Las biografías de Ribera y Garma en J. Ernesto MARTÍNEZ FERRANDO, «Los académicos archiveros», Boletín de la Real Academia de Buenas Letras de Barcelona, 25 (1955), pp. 355-379 (especialmente las pp. 355-360). 
que se engrandezcan sus méritos y se dissimulen o disminuyan sus defectos: dulce violencia, que temen con razón los mejores críticos; pues aunque un historiador debe olvidar por la verdad las nativas obligaciones de Patricio (y no, como erradamente dixo Letti, las de la Religión) pero como es propensión, de que dificilmente se desprenden aún los varones más íntegros, es siempre temible algún descuydo... La segunda mira al propio Soberano; por cuyos interesses suele la ambición u otras passiones, fixando en ellos la vista, retirarla de la equidad y aún de la Religión, a costa de graves perjuicios, que menciona el Cardenal Luca.. La tercera se dirige al genio comín de la nación: regla en que persistió Bucardo Struvio formando el caracter de todas las de Europa e indicando a Mons. de la Mothe le Vayer que escribió de lo mismo... Sobre esta ispección, es preciso no confundir el genio con la costumbre».

Y más adelante dirá:

"Los escritores nacionales en la historia de su reyno deben ser preferidos a los estrangeros; lo persuade la autoridad, la experiencia y la razón». Existen, sin embargo excepciones: "quando no sabe moderar el amor patricio...o bien quando se entrega con sobrada credulidad a las fabulas populares, ligereza no estraña de que se lastiman los criticos. Por este motivo es desaprobable, como dixe, el Padre Barrellas, aunque Cathalán, en la historia de nuestros Condes, quando en la misma muy atendido el padre Diago Valenciano, por su solidez y documentos. La otra excepción, respectiva a los hechos, procede quando la verdad de ellos desautoriza notablemente el honor del Príncipe o de la patria» ${ }^{\text {s3 }}$

Aunque se persigue la verdad, se hace bajo unos límites. Si la veracidad actua en menoscabo del honor del príncipe y de la patria, por ejemplo, Mora considera excusable disimular los hechos. Su patria es evidente que era Cataluña pero su príncipe había sido Felipe $\mathrm{V}$, dos excusables devociones que, históricamente, no siempre habían congeniado.

Después de advertir sobre este punto y asumir que las flaquezas aquejan incluso a los más honestos cronistas, continúa escrutando las aptitudes intrínsecas o inherentes al buen historiador: la integridad o bondad de costumbres, la prudencia y la erudición. Sigue con las circunstancias extrínsecas: edad madura, eminencia del empleo, lugar y tiempo en qué escribe y medios y motivo. Finalmente, completan el trabajo unos anexos sobre los carácteres de la escritura, las abreviaturas, la ortografía y el origen y formación de las lenguas románicas.

La exposición metodológica del marqués de Llió, sin embargo, aunque sobresaliente, quedó incompleta. Formaba parte de un programa auspiciado por la Academia que se suspendió después de su temprana muerte en 1763. Pero para entonces, los falsos cronicones estaban ya proscritos y desacreditados entre la mayoría de los literatos. En Cataluña, durante la segunda mitad del siglo XVIII, el criticismo en sus variantes bibliográfica y documental había ocasionado una profunda innovación técnica

33. Josep de MORA Y CATÀ, «Observaciones sobre los principios elementales de la historia», Real Academia de Buenas Letras de la ciudad de Barcelona; origen, progressos y su primera junta general baxo la protección de Su Magestad, con los papeles que en ella se acordaron, tomo 1. Francisco Surià, Barcelona [1756], pp. 105-107 y 214-216. 
pero apenas había afectado a la razón. La tradicional razón cristiana continuó dominando frente a la «moderna» razón laica, de manera particularmente acusada en el ámbito de la historia eclesiástica. Como asevera Ramon Grau, «la historiografía crítica eclesiástica de los siglos XVII y XVIII tenía marcado un límite metodológico importante. Una vez establecida la autenticidad del documento, los hechos consignados por él eran considerados igualmente auténticos, con independencia de su credibilidad a la luz de la razón natural» ${ }^{34}$. Los milagros, por ejemplo, eran gustosamente admitidos si estaban avalados por un soporte documental fiable. Más allá de la precisión documental o la exactitud cronológica, la crítica histórica española y catalana va a considerar con muchos recelos los valores enciclopedistas franceses. Las opiniones que sobre la historia de España esgrimían Montesquieu, Voltaire o Diderot tampoco permitían una fácil asunción. Cuando bajo formas tan crudas delataban estos autores una historia de España falsamente gloriosa, construida sobre supersticiones y quimeras y con evidentes tachas en el orden de la tolerancia y la civilización incentivaban una mayoría de respuestas patrioteras que con orgullo recurrían al definitivo «Santiago y cierra España». Es evidente que este hecho colaboró muy poco en el restablecimiento de la conciencia nacional catalana, aletargada desde 1714. A pesar de todo, una minoría de autores, con simpatías hacia el enciclopedismo pero profundamente religiosos, es decir, eclécticos, van a hacer de la historia una lectura más escéptica. El diagnóstico va a poner de manifiesto ciertas sombras a las cuales será preciso poner remedio ${ }^{35}$. El compromiso hacia esta historia crítica que habla de la razón va a ser más o menos asumido por los historiadores barceloneses Antoni de Capmany y Joan Francesc Masdeu. La historia crítica, por tanto, durante la segunda mitad del Setecientos se va dividir en dos: por un lado, la ya tradicional historia crítica en relación a la técnica de la disciplina y por otro, la más reciente historia crítica en relación al debate sobre la razón. Mientras la primera fue asumida con cierto envanecimiento por la mayoría, la segunda fue acometida por casi todos los autores, de manera particular después del estallido revolucionario de 1789.

El canónigo gerundense Francesc Dorca es un caso paradigmático de esta postura crítica. Dorca (1736-1806), estudiante y profesor en la Universidad de Cervera, discípulo de Josep Finestres y, finalmente, canónigo de la catedral de Gerona, escribió entre 1803 y 1805 una trilogía de obras en donde se combaten, directa o indirectamente, los valores de la Ilustración francesa y, de manera particular, los principios políticos y sociales de Rousseau ${ }^{36}$. Este autor, al mismo tiempo, publicó a finales del Setecientos una obra de carácter histórico, titulada Colección de Noticias para la his-

34. Ramon GRAU, «Els intel-lectuals...», 1995, p. 339.

35. Francisco SÁNCHEZ-BLANCO PARODY, «El pensamiento crítico» en Europa y el pensamiento español del siglo XVIII, Alianza, Madrid, 1991, pp.. 134-172.

36. Montserrat JIMÉNEZ SUREDA, El canonge Dorca i la Il-lustració gironina, trabajo de doctorado, Universidad Autónoma de Barcelona, Bellaterra 1992; Javier ANTÓN PELAYO, «Los ilustrados del absolutismo en Cataluna», Congreso Internacional. El conde de Aranda y su siglo, Zaragoza, 2-5 diciembre 1998 (en prensa). 
toria de los santos mártires de Gerona, en donde aprovechaba el prólogo para hacer una elocuente exposición del espíritu crítico que había aplicado a su obra. En el orden de la crítica bibliográfica se muestra seguidor de Nicolás Antonio, Jacinto Segura y el cardenal Aguirre y denuncia, entre otros, a su compatriota Antoni Vicenç Doménech, acusándolo de poco discernimiento en su Historia de los santos de Cataluña (1602), pues muy pocos de sus protagonistas merecerían la aprobación de la crítica. En el orden de la crítica documental reproduce las consignas de Teodorico Ruinart y Honorato de Santa Maria ${ }^{37}$ sobre las clases de actas genuinas y verdaderas, aunque admite que a veces la crítica peca de excesivo rigor y, de este defecto acusa a los célebres Tillemont y a Papebroch por cuestionar ciertos mártires locales. Entre las acusaciones de rigorismo y las prevenciones políticas, la crítica se hizo tan vaporosa que acabó adoptando tonos enfermizos.

\section{LA HISTORIOGRAFÍA ILUSTRADA Y NACIONAL EN CATALUÑA}

\section{a) Pere Serra i Postius}

El tendero de telas Pere Serra i Postius, austracista calado de fervor religioso y amor a la patria, representa una singular continuación del legado de Feliu de la Penya. Fue coleccionista de libros y documentos, autor muy prolífico durante la primera mitad del siglo XVIII y miembro de la Academia de Buenas Letras desde 1729. En su principal obra, titulada Prodigios y finezas de los santos ángeles hechos en el Principado de Cataluña (1725), pone de manifiesto su predilección -como era habitual en la época- por el pasado medieval, aunque éste es contemplado desde una perspectiva acentuadamente religiosa y bajo un trasfondo político dirigido a demostrar las particularidades de Cataluña. Serra i Postius remarca el sustrato goticista del Principado que, junto a la debilidad de la presencia árabe, dotan a esta tierra de un ardor religioso muy superior al del resto de territorios hispanos. Estos buenos principios se demuestran a través de la abundancia y la calidad de los ministros angélicos que ha producido, clara muestra -según Serra i Postius- de que Cataluña es un país elegido por Dios. El acentuado sentimiento patriótico, la admisión de premisas imbuidas de irracionalismo religioso y la poca rigurosidad en la aplicacion de los preceptos criticistas aproximan la obra de este autor a una condición rayana al folklore. De hecho, el criticismo de principios del siglo XVIII en Cataluña era asumido desde dos posiciones, una más estricta y otra más distendida. En sentido riguroso una tradición sólo era verdadera si iba amparada por documentos fidedignos y, desde una postura más laxa, no se podía acusar de falsa a una tradición si no se demostraba positivamente su falta de rigurosidad documental. Es evidente que Serra i Postius siguió el segundo criterio, más moderado y, por tanto, más positivo respecto a las tradiciones del pasado. Si a

37. Thierry Ruinart (1657-1709), maurino y discípulo de Mabillon, autor de una obra titulada Acta primorum martyrum sincera et selecta (1689); Honorato de Santa Maria -o Blas Vauxelle- (1651-1729), carmelita, autor de unas «Reflexiones sobre las reglas y el uso de la crítica» incluidas en sus Dissertations historiques et critiques sur les ordres militaires anciens et nouveaux (1713). 
esta pauta se le añaden los dictámenes del propio autor sobre su trabajo y ciertos halagos propios de los prologistas, sus historias pueden adoptar un barniz criticista con el cual nunca llegó a comulgar ${ }^{38}$.

\section{b) Jaume Caresmar}

Jaume Caresmar también fue un erudito anticuario como Serra i Postius, pero su método estaba amparado por un criticismo documental mucho más severo. Era un hombre de orígenes menestrales, profundamente religioso, que ingresó como canónigo del monasterio premostratense de Bellpuig de las Avellanas en 1742. Allí el abad Daniel Finestres -hermano del eminente profesor de Cervera Josep Finestres- le despertó el interés por la historia. Trabajó en la ordenación y transcripción depurada de los documentos de varios archivos, empezando por el de su monasterio y continuando después por los de Sant Cugat del Vallès, Gerri de la Sal, la colegiata de Ager y la catedral de Barcelona. Entre sus mentores, además de Daniel Finestres, se encuentran Josep Pons -historiador del monasterio de Sant Cugat-y los eruditos de la Real Academia de Buenas Letras de Barcelona a partir de su ingreso en 1750. Por esta fecha, la Academia estaba plenamente orientada hacia la renovación metodológica gracias a los desvelos del marqués de Llió, con el cual Caresmar colaboró de forma activa. Participó también con frecuencia en las tareas académicas, ya como lector de disertaciones, ya como revisor de los trabajos de historia. Asimismo, colaboró con dos grandes proyectos auspiciados desde las cortes borbónicas de Madrid y París. Por un lado, proporcionó buena parte de los documentos empleados para ilustrar los capítulos relativos a las diócesis de Vic y Barcelona de la España Sagrada de Enrique Flórez y, por otro lado, participó en las colecciones diplomáticas francesas dirigidas por Moreau.

La enorme labor archivística del «Mabillón catalán»-según lo apodó Joaquín Traggia-, continuada tras su muerte por sus discípulos Jaume Pasqual y Josep Martí, se tradujo en una extensa producción historiográfica que, sin embargo, ha quedado desvanecida debido a que sólo una pequeña parte fue publicada en vida del autor. La mayoría quedó manuscrita y, una buena porción de ella, ha terminado extraviada o destruida. Por otra parte, su rigor metodológico contrasta con un cierto descuido en la redacción de unos trabajos que casi siempre se quedaron en esbozos de proyectos de mayor envergadura. Su recolección de noticias se tradujo en catálogos de manuscritos y documentos de archivo, diccionarios y obras de temática eclesiástica y civil.

Dentro de las monografías de historia eclesiástica y, de manera particular, en el enrevesado tema de la hagiografía, Caresmar hizo gala de una coherencia respecto a los procedimientos de revisión documental empleados por las autoridades mauristas y bolandistas aunque sin cuestionar en ningún momento la verosimilitud del objeto estudiado a los ojos de la razón natural. La oscilación de criterios que mostró en este tema y los entusiasmos e inquinas que despertó no son más que un alegato a su empeño

38. Ramon GRAU, «Les batalles», 1996, pp. 172-175 y José Luis BETRÁN, Antonio ESPINO y Lluís Ferran TOLEDANO, «Pere Serra i Postius y el criticismo...», 1992, pp. 321-327. 
metodológico. En 1764, publicó su primera obra, titulada Sanctus Severus episcopus et martyr, sedi et civitati barcinonensi noviter assertus et vindicatus, en qué refutaba las dudas que había planteado Gregorio Mayans respecto a la peculiaridad de San Severo, obispo de Barcelona. El intelectual de Valencia pretendía confundir al obispo barcelonés con el obispo de Rávena y Caresmar, adoptando el criticismo laxo de Serra i Postius y bajo un cierto impulso patriótico, vindicó al venerado prelado y mártir para satisfacción de la historiografía popular y el cabildo barcelonés que, a partir de 1770 , le abrió las puertas de su archivo para que trabajase a sus anchas.

Unos años después, el obispo de Barcelona Gabino Valladares pidió a Caresmar una valoración de las pruebas referentes a la vida y martirio de Santa Eulalia, cuya liturgia pretendía restaurarse ante las demandas populares. Las conclusiones del historiador, sin embargo, fieles al rigor documental, desmontaron buena parte de la tradición que se basaba en un texto apócrifo del siglo XVII. Este resultado fue muy mal asumido por los devotos de la patrona, de tal manera que Caresmar fue objeto de una campaña de desprestigio que llegó incluso a las agresiones físicas por las calles de Barcelona. Además de la inquina del cabildo de canónigos -que prohibió la entrada del erudito a su archivo- y las invectivas lanzadas en un opúsculo en defensa de la santa por Domènec Ignasi Bòria, un tocayo de la Academia de Buenas Letras, Caresmar fue inspirador de una buena cantidad de degradantes poesías satíricas. Una de ellas decía,

Un blanquillo con valona
sujeto de poco seso
está deteniendo el rezo
de Eulalia, nuestra patrona.
Con motivo Barcelona
dirá de este gran jumento:
que se vuelva a su convento
pues que todo esto dimana
de ser él una avellana
que no tiene nada dentro

A pesar del enfrentamiento de Caresmar con el barroquismo recalcitrante, su posición no es ni mucho menos conciliable con el racionalismo crítico de la llustración. Sólo en la apertura temática -basada en el progresivo desplazamiento de la historia eclesiástica y la irrupción de la historia civil- se demuestran atisbos de un cierto influjo enciclopedista. A través de la Carta al barón de La Linde en la que se demuestra ser Cataluña en lo antiguo más poblada, rica y abundante que hoy y del Discurso sobre la agricultura, comercio y industria, con la inclusión de la consistencia y estado en qué se halla cada partido o veguería de los que componen el principado de Cataluña se puede hablar de un Caresmar receptivo a los temas demográficos, geográficos, económicos y, en definitiva, a esa historia más humana, más interpretativa y más burguesa que caracterizará los trabajos de Antoni de Capmany.

39. Ramón de ABADAL Y DE VINYALS, «Doscientos años de historia de Cataluña en la Real Academia de Buenas Letras», Boletín de la Real Academia de Buenas Letras de Barcelona, 25 (1953), p. 331. 


\section{c) Antoni de Capmany}

Después de abandonar la carrera militar en 1770, Campany compaginó su animada actividad política con una fecunda labor intelectual y literaria. En sus obras combinó preceptos que, en principio, podrían resultar contradictorios pero que, dentro del marco de la Ilustración española, adquieren una indulgente congruencia. Capmany se identifica con la tradición católica, pero asume el principio de progreso de la Ilustración francesa e inglesa, aunque matizado, pues, contrariamente a las opiniones de los filósofos franceses, no asume el generalizado aserto que ejemplifica a España con el atraso secular. Trata de rebatir esta visión negativa demostrando, mediante datos empíricos, determinados aspectos provechosos de la idiosincrasia nacional, por ejemplo, la eficacia de la lengua castellana y la laboriosidad de los catalanes. El caracter conciliador de su proyecto de renovación de España es lo que ha dado pábulo a la suspicacia de los puristas, por un lado, y a la utización desnaturalizada de los idólatras, por otro.

Dentro de la historiografía catalana, Capmany es el artífice de la síntesis entre la erudición y la historia narrativa que caracteriza a los historiadores modernos. Como señaló Vilar, «Capmany ha poseído las cuatro cualidades fundamentales del historiador: seriedad en la documentación de archivo, crítico de los documentos, sentido de síntesis, calidad en la presentación de las obras ${ }^{40}$. El cambio cualitativo también está en relación a los nuevos intereses temáticos. La tradicional fascinación por los reyes y las batallas va a recular en beneficio de materias más modestas -como las costumbres, las leyes, la cultura o la economía-, aunque más antiheróicas, más civiles y más burguesas. De hecho, Capmany se pone al servicio del Ayuntamiento de Barcelona y la Junta de Comercio de dicha ciudad para defender los intereses de la emergente sociedad burguesa catalana a través del análisis histórico-económico. Fruto de esta alianza nacen el Discurso económico-político en defensa del trabajo mecánico de los menestrales y de la influencia de sus gremios en las costumbres populares, conservación de las artes y honra de los artesanos (1778), las Memorias históricas sobre la marina, comercio y artes de la antigua ciudad de Barcelona (1779), el Código de las costumbres marítimas de Barcelona, hasta aquí vulgarmente llamado Libro del Consulado (1791), el Suplemento a las Memorias históricas (1792) y las Cuestiones críticas sobre varios puntos de historia económica, política y militar (1807).

Su visión de la historia de Cataluña y España es pragmática y presentista. Por ello, hace caso omiso a los mitos nacionales característicos de la historiografía barroca, utiliza documentación de primera mano que, por su naturaleza, no ha sido objeto de manipulaciones ni interpretaciones partidistas y, finalmente, emplea la crítica racionalista para ahuyentar los hechos inverosímiles. Capmany es, posiblemente, el principal historicista que defendió una idea de progreso basada en la tradición económica, política e institucional de Cataluña frente al uniformismo y la centralización

40. Pierre VILAR, «Capmany i el naixement...», 1983, p. 86 (traducido del catalán). 
que clamaban los racionalistas de corte francés ${ }^{4}$. Paralelamente, su inclinación utilitarista le lleva a menospreciar en numerosas ocasiones la lengua catalana tildándola de «idioma provincial anticuado». Por ello, no duda en traducir y adaptar en sus obras los documentos escritos originalmente en catalán. Este tipo de actitudes le han acarreado la desconfianza de los ideólogos del nacionalismo filológico, presente ya en el siglo XIX y tan de boga en la actualidad. Este detalle, sin embargo, no ha conseguido empañar la calidad historiográfica de Capmany ni su importancia como germen del catalanismo contemporáneo ${ }^{42}$.

\section{d) Joan Francesc Masdeu}

La concepción historiográfica de Masdeu tiene muchas similitudes con la historia ilustrada de Capmany, sobre todo, en lo referente al empleo de la crítica y a la ampliación del campo histórico. El primer aspecto se manifiesta en su radical rechazo al ipse dixit -cuestionando incluso las Sagradas Escrituras-, la valoración de las pruebas documentales mediante el empleo de las ciencias auxiliares y el rechazo de los anacronismos, las deducciones interesadas y los sucesos inverosímiles a la luz de la razón. El segundo aspecto, supone la participación de Masdeu en una nueva concepción de la historia en donde monarcas y batallas compiten en protagonismo con otros temas como el clima, el comercio, las costumbres, el temperamento, la cultura, la población, el gobierno, la agricultura o la artesanía, es decir, con la historia civil.

Estos saludables planteamientos, sin embargo, se plasmaron en una producción historiográfica afectada por el claroscuro. Tal vez, las vicisitudes de su azorada biografía puedan explicar este impulso contradictorio. Masdeu fue un catalán nacido en $\mathrm{Pa}$ lermo, jesuita desterrado en Italia por Carlos III aunque regalista, apologista de la cultura española frente a las invectivas francesas e italianas y partidario de las reformas políticas como antídoto contra la propagación de la Revolución Francesa. Su principal obra es la Historia crítica de España y de la cultura española (1784-1805, 20 volúmenes más 5 inéditos), monumento inacabado en qué combina esa hipercrítica -de la que ha sido con frecuencia acusado- con la apologética y el catolicismo nacional.

A pesar de las pruebas, no transige en aceptar héroes populares como el Cid, Fernán González o la presencia de Carlomagno en Cataluña, pero es permisivo, amparándose en la carencia de argumentos negativos, con las tradiciones piadosas referentes a la cristianización de la península (venida de Santiago y San Pablo o existencia de la Virgen del Pilar). En este aspecto, mantiene una postura muy parecida a la de Enrique Flórez y a la de la inmensa mayoría de los eruditos inflamados de nacio-

41. Ramon GRAU y Marina LÓPEZ, «Antoni de Capmany: el primer model del pensament polític català modern» en Albert BALCELLS (coord.), El pensament polític català del segle XVIII a mitians segle $X X$, E. 62, Barcelona, 1988, pp. 13-40 (especialmente las pp. 33-40).

42. Sobre este particular discrepan Grau/López y Fernández/Cantero. Ramon GRAU y Marina LÓPEZ, «Antoni de Capmany...», 1988, pp. 13-40 y Francisco José FERNÁNDEZ DE LA CIGOÑA y Estanislao CANTERO NÚÑ̃EZ, «Un catalán españolísimo», Antonio de Capmany..., 1993, pp. 409-414 y 366-370. 
nalismo. Un nacionalismo, sin embargo, que no es lesivo para Cataluña. Masdeu mantiene una idea unitaria pero no uniforme de España, plantea una diferencia étnica y lingüística entre Iberia (la Tarraconense) y España (la Bética-Lusitania), se siente orgulloso de su patria aunque su reivindicación de la particularidad catalana se circunscriba al ámbito cultural, obviando cualquier tipo de recuerdo político aunque añorando el tiempo anterior a los Decretos de Nueva Planta ${ }^{43}$.

\section{e) La Real Academia de Buenas Letras de Barcelona}

La Academia de Buenas Letras tenía su origen en la de los Desconfiados (activa entre 1700 y 1703), reestablecida como Academia «sin nombre» en 1729 y admitida bajo protección real en 1752. Desde el principio, la Academia se propuso dos grandes objetivos, la preparación de una historia de Cataluña y la redacción de un diccionario de la lengua catalana. Aunque a lo largo del Setecientos ninguno de los dos proyectos llegó a materializarse, la Academia logró incentivar la presentación de ensayos alusivos a estas dos temáticas. Sin lugar a dudas, el momento de mayor actividad de la Academia fue a mediados de la centuria, cuando el marqués de Llió, con sus Observaciones sobre los principios elementales de la Historia y su impulso crítico, promovió la presentación de un buen número de comunicaciones. Después de su muerte en 1762, la institución tuvo una trayectoria más lánguida, con un ritmo de trabajo más lento y discontinuo.

Aunque la calidad de los trabajos de historia presentados es muy desigual, el objeto, la historia de Cataluña, «revela un interés por mantener vivas las raices distintivas del Principado, en un momento en que el poder omnímodo de la monarquía, preconizado por los teóricos del Despotismo Ilustrado parece irse imponiendo progresivamente $\gg^{44}$. No significa, ni mucho menos, que los discursos académicos fuesen perversos recuerdos austracistas dentro de un escenario borbónico, sino que la actividad de eruditos de segunda o tercera fila, todavía muy imbuidos de tradicionalismo barro$\mathrm{co}$, continuaba reproduciendo los viejos esquemas y las antiguas temáticas, inocuas porque no fueron publicadas. La mayoría de las comunicaciones presentadas se refería a la historia secular y eclesiástica de los tiempos condales de Cataluña y a la invasión de los moros, es decir, a los primeros siglos de la Edad Media.

Dentro de la historia eclesiástica, hay al menos dos aportaciones destinadas a describir el origen y el fundamento del culto dado a Carlomagno en la Catedral de Gerona. Una de ellas la leyó en 1753 el canónigo de la catedral de Gerona Josep Bastero i Vilana, miembro de una saga de eminentes eclesiásticos austracistas, y lleva por título «Origen y fundamentos del culto dado por la Santa Iglesia de Gerona a Carlo Magno con la expresión de las variaciones que ha tenido y de quanto en el día se practica». La otra es la presentada en 1788 por Joan Francesc de Molina, titulada «Sobre la conquista de Gerona y antigüedad de su catedral», en qué, contra la opinión

43. Roberto MANTELLI, «Nationalism, xenophobia...», 1982, pp. 209-260.

44. Miguel PÉREZ LATRE y David ASENSIO VILARÓ, «Cultura histórica en Cataluña...», 1988, p. 241. 
del Marqués de Mondejar -que cuestionaba la presencia del emperador en la ciudad catalana-, aduce testimonios de varios libros de visitas pastorales. De hecho, la supuesta ida de Carlomagno a la ciudad de Gerona se había ido engalanando a lo largo de los siglos de tal manera que su persona era venerada como la de un santo ${ }^{45}$ y su leyenda había permitido en tiempos pasados justificar el pactismo innato de Cataluña ${ }^{46}$.

Esta tradición, sin embargo, había sido progresivamente erosionada como consecuencia del empleo de la crítica y del impulso de la política. Además de Mondejar, también Masdeu y el canónigo gerundense Francesc Dorca reprobaron la conquista de Gerona por Carlomagno. La actitud histórico-política de Dorca -junto con la de otros profesores y humanistas cervarienses, como Joan Antoni Mujal y Onofre Pratdesaba- representa una muestra del ideario de aquella universidad dieciochesca, una doctrina que estaba en abierta oposición con la tradición catalana. Por contra, todavía a finales del siglo XVIII, el escaso dinamismo de la Academia borbónica continuaba siendo uno de los principales focos de las viejas reivindicaciones nacionales.

La historia nacional catalana a finales de la centuria experimentó sobre todo una mutación metodológica como consecuencia del influjo criticista. El optimismo que los eruditos del Barroco profesaban hacia las argumentaciones jurídicas se va a transformar en Capmany y Masdeu en confianza respecto a valores más ordinarios -pero más modernos- como la laboriosidad y la cultura. Se continuó exaltando el papel de las instituciones autóctonas aunque atribuyéndoles influjos benefactores muy diferentes y, por supuesto, superando el tradicional enfrentamiento de Cataluña con sus vecinos.

Salvo algunas excepciones -como por ejemplo, la del enfrentamiento de Masdeu con el padre Risco, continuador de la España Sagrada, por el tema del Cid-los historiadores catalanes se sumaron al foro de interlocución español para repeler las tópicas invectivas recibidas por el racionalismo francés. Dentro del proyecto común, los historiadores más comprometidos no se amilanaron después del estallido revolucionario francés y las agresiones bélicas que padeció el Principado durante los años 17931795 y 1808-1814. Capmany sería un caso ejemplar. Otros intelectuales, más timoratos con el desarrollo de los acontecimientos, cerraron filas convirtiéndose en los ilustrados del absolutismo en Cataluña. El canónigo Dorca, después de cuestionar con un excelente rigor crítico el mito de Carlomagno, va a iniciar la centuria reivindicando el mito de Don Pelayo.

45. Montserrat JIMÉNEZ SUREDA, «Els orígens d'un sentiment d'identitat col-lectiva: el mite de Carlemany», L'Església catalana sota la monarquía dels borbons. La catedral de Girona en el segle XVIII, Publicacions de l'Abadia de Montserrat, Barcelona, 1999, pp. 265-270.

46. Jesús VILLANUEVA, Los orígenes carolingios..., 1994. 